\title{
Schemas and Frames ${ }^{1}$
}

\author{
(Forthcoming in Sociological Theory)
}

\author{
Michael Lee Wood \\ mwood3@nd.edu \\ Dustin S. Stoltz \\ dstoltz@nd.edu \\ Justin Van Ness \\ jvanness@,nd.edu \\ Marshall A. Taylor \\ mtaylo15@nd.edu
}

${ }^{1}$ This paper benefited immeasurably from conversations with Feyza Akova, Omar Lizardo, and Terry McDonnell, to whom we are grateful. Similarly, we sincerely appreciate the detailed and thoughtful comments we received from three anonymous reviewers and the guidance from Mustafa Emirbayer. We also want to thank the larger community of scholars working at the intersection of culture and cognition for enriching our work both as individuals and as a team. Corresponding Author: Michael Lee Wood, Department of Sociology, University of Notre Dame, 4060 Jenkins-Nanovic Hall, Notre Dame, IN 46556, USA. Email:mwood3@nd.edu. 


\begin{abstract}
A perennial concern in frame analysis is explaining how frames structure perception and persuade audiences. In this paper, we suggest that the distinction between personal culture and public culture offers a productive way forward. We propose an approach centered on an analytic contrast between schemas, which we define as a form of personal culture, and frames, which we define as a form of public culture. We develop an "evocation model" of the structure and function of frames. In the model, frames are conceived as material assemblages that activate a network of schemas, thereby evoking a response when people are exposed to them. We discuss how the proposed model extends, and clarifies, extant approaches, and consider new directions for future research.
\end{abstract}




\section{INTRODUCTION}

Sociologists use the concepts of schema, frame, and framing to understand how perceptions are organized and altered between individuals and groups, often (but not always) in attempts at persuasion. Since their introduction, different ways of defining these concepts have emerged, some more tractable than others. In this paper, we propose a synthetic framework grounded in recent developments in culture and cognition studies. In what follows, we distinguish our framework from previous approaches while arguing that our formulation clarifies and maximizes the analytic utility of these concepts.

Our intervention takes as a starting point the distinction between personal and public culture recently articulated by Patterson (2014) and Lizardo (2017), who build on the work of anthropologists like Spiro (1987), Shore (1998), D’Andrade (1995), Bloch (2015), and Strauss and Quinn (1997). In this approach, personal culture is understood as aspects of a person's memory which are shared (i.e., not idiosyncratic) and learned (i.e., not innate). This form of culture can be further divided into nondeclarative (e.g., habits, skills, judgments, biases) and declarative culture (e.g., explicitly recollected events, memorized facts, songs, and phrases).

Public culture, in contrast, is located outside of persons and therefore always material, sensuous, and tangible. This public form includes everything potentially available for interaction, like physical objects and settings, as well as sounds, human and non-human bodies, texts, and conversations. While distinct (and thus not reducible to either one or the other), personal and public culture are interlinked (Shore 1991). For example, while cultural symbols take an objectified, external form, they must also be coupled with the conceptions evoked in the minds 
of the actor perceiving the symbol (Lizardo 2016:200; Turner 1967:20). This formulation aligns with sociologists working at the intersection of culture and cognition studies (e.g, Brekhus 2015; Cerulo 2014; DiMaggio 1997; Lizardo 2014), as well as culture and materiality scholars (Dominguez-Rubio 2014; Griswold, Mangione, and McDonnell 2013; Klett 2014; McDonnell 2010; Sonnett 2004; Stoltz and Taylor 2017).

With this distinction as our point of departure, we further distinguish the concept of schema, which we propose is a nondeclarative form of personal culture, from that of frame, which we conceive as a form of public culture which activates schemas. Second, we make an analytical distinction between a frame, which is always situational and material, from a model of a frame, which is the set of declarative instructions or nondeclarative skills used to recreate a frame. From this perspective, then, framing refers to the physical assembling of a frame, while frame modeling refers to the implicit or explicit creation of a model of a frame. We argue that distinguishing schemas from frames along the personal/public divide, and distinguishing frames from models of frames, maximizes the usefulness of these concepts for contemporary research as it affords a logically coherent, cognitively tenable, and empirically productive framework to analyze persuasion and perception.

Building on these distinctions, we propose an evocation model for frame analysis. In contrast to approaches defining frames as interpretive packages publicly transmitted and internalized by actors, we propose that frames are better thought of as situational material assemblages that activate schemas previously internalized by persons. Rather than impose meanings, frames evoke meanings. Persons compose frames through the (re)assembling of the materiality of situations which, when perceived, activate networks of schemas that evoke 
associated responses. Frame composition may be instrumental or expressive and may involve just one articulator (e.g., a solo artist) or a team (e.g., protesters). Actors may develop models of a frame either automatically through repeated experience with particular frames, or through conscious deliberation and reflection. Models of frames may influence the reconstruction of frames in situ.

\section{[Table 1. About Here]}

\section{SCHEMAS}

What are Schemas?

The modern concept of "schema" can be traced back to the 18th century in Immanuel Kant's Critique of Pure Reason (1998 [1781]). "Schema" was later elaborated by the psychologists Frederic Bartlett (1932) and Jean Piaget (1952) in the early 20th century to account for the role of an individual's prior experiences in shaping present responses. The concept underwent a renaissance in the 1970s, with advancements in artificial intelligence (Minsky 1974), motor skill research (Schmidt 1975), cognitive psychology (Rumelhart 1975, 1980), linguistics (Fillmore 1975), political science (Axelrod 1973), and developmental psychology (Mandler 1978). In sociology, the term "schema" first appears in this contemporary form in Cicourel (1981) ${ }^{2}$ but remained relatively dormant until Sewell's (1992) recasting of Giddens'

\footnotetext{
2 Although, see our references to Goffman (1974:21), and Lizardo (2004) on Piaget's influence on
} Bourdieu. 
(1979:62-64) conceptualization of the duality of structure as the recursive linkage of schemas (previously rendered as "rules") and resources. ${ }^{3}$

Our conceptualization of schema-see Table 1 for a summary of key definitions-follows the standard treatment found across the cognitive sciences today (Ghosh and Gilboa 2014) and used increasingly by sociologists (Cerulo 2010:117; DiMaggio 1997:267; Patterson 2014:4; Vaisey 2009:1686). However, because contemporary uses of the term vary in significant ways within sociology, it is necessary to distinguish our conceptualization from others. Three aspects, in particular, are worth mentioning.

First, we define schemas as a form of personal culture-literally, entrenched multi-modal (i.e., visual, aural, tactile, olfactory, kinesthetic, etc.) neural associations developed via repeated embodied experience (i.e., perceptual, sensorimotor, interactional) and stored in long-term memory. Schemas are cultural because they are learned and may be shared and distributed across persons, provided they have similar life histories and experiences (Bloch 2015; Iacoboni 2009; Lizardo 2009). ${ }^{4}$ The conceptualization of schema used in this article stands in contrast to uses of the term which, following Sewell (1992), are ambiguous as to whether they are talking about an external pattern or an internal mental structure (for example Somers 1999:125; Spillman 2016:441-442; Swidler 2001:83-88; Swidler and Arditi 1994:322). Because in our formulation schemas are memory structures located in persons, our definition is not compatible with those

\footnotetext{
${ }^{3}$ There is an additional sense in which the term schema has been used in sociology which refers to some sort of organization of one's own theory, for example, Parsons' means-ends schema (1935) - using the term in this sense is far less common in contemporary sociology.

${ }^{4}$ We do not refer to "cognitive" schema, because all schema are cognitive. Furthermore, it is common for sociologists to refer to "cultural" schemas, presumably to differentiate from schema which are not learned. Because humans begin the process of schematizing in the womb, however, identifying non-cultural schema remains quite difficult. The strongest candidate would be that for facial recognition (Slater and Quinn 2001).
} 
who deem them "virtual" objects, irreducible to "any particular location in space or time" (Sewell 1992:8).

Second, we define schemas as lacking specific content (see also Hutto and Myin 2012, 2017; Rumelhart and Ortony 1977:101-105). These neural associations retain relational information while producing "variables" which lack "unit detail" (Boutyline 2016; Ghosh and Gilboa 2014; Goldberg 2011) and do not necessarily pre-specify default elements. ${ }^{6}$ Schemas lack unit detail because the process of schematization involves a structured "forgetting" of detailed information (of the sort that might be retained in declarative memories) and the retention of features that are highly-correlated across multiple exposures (McClelland and Rumelhart 1985). ${ }^{7}$ This process is precisely why schemas are reusable (or "transposable") across variable situations. Therefore a schema should not be conceived as an "image" or a "representation" in the lay sense of these terms.

Finally, schemas are a form of nondeclarative memory (Squire 2004, 1992) - acquired, used, and altered through a repeated, automatic process of schematization from experience (Lizardo 2017; Lizardo et al. 2016). ${ }^{8}$ Schemas are not encoded in memory quickly (as one might memorize a word or phrase, for instance), but rather through a "slow learning" process of habituation, built through the ongoing exposure to redundant aspects of interaction in social and

\footnotetext{
${ }^{5}$ That Sewellian schemas are "virtual" (and therefore never reducible to any particular location in space and time) renders the concept incompatible with the personal/public dichotomy on ontological grounds as the latter approach rejects substance dualism, and presumes that culture is "localizable."

${ }^{6}$ Schemas often do have "default" content (e.g., redness or houseness or wombatness) that result from recurrent biases in experience, but such elements are fuzzy, gradational elements, which remain "under-specified" (see Lakoff 1999; Rosch 1973, 1983, 1999; Rumelhart and Ortony 1977:110-111).

${ }^{7}$ Furthermore, unlike the sorts of "deep structures" proposed by Levi-Strauss in his later work, schemas are not innate cognitive structures, but rather emerge from repeated experience and are therefore "synthetic" in the Kantian sense.

${ }^{8}$ Although, we can certainly be conscious of the cognitive output of schema.
} 
physical spaces. As nondeclarative memory, schemas are also automatically activated by qualities of the current situation, through pattern recognition, pattern filling, and, in turn, pattern updating. In sum, we argue that schemas are a personal, underspecified, and nondeclarative form of culture. To give a better sense of the sort of shift in conceptualization which this would entail, we review two kinds of schemas generally neglected by sociologists-image schemas and foundational schemas - which exhibit the three characteristics discussed above, and which we offer as useful default notions of the schema concept.

Image Schemas

Schemas vary in complexity, with the simplest schemas often referred to as image schemas. Image schemas can be conceived as "simple spatial stories" (Mandler and Cánovas 2014), which emerge from the most redundant aspects of perceptual and bodily interaction with a material and spatial world. These primitive associations are stored in long term memory (Johnson 2013 [1987]), and form the basic building blocks of more abstract thought. This concept emerged in the 1980s out of the collaborative work of the philosopher Mark Johnson and the linguist George Lakoff, brought together by their mutual concern with metaphor, resulting in Metaphors We Live By (2008 [1980]; for the abridged version see Lakoff and Johnson 1980). In this initial formulation, they referred to source domains for conceptual metaphors as “experiential gestalts." In the late 1980s, Lakoff (2008 [1987]) and Johnson (2013 [1987]) began to use the term "image schema" instead, and it quickly spread across disciplines with some variations in terminology (Mandler and Cánovas 2014). 
The initial evidence for image schemas was the striking consistency among metaphors in cross-linguistic data, though the concept also finds support in developmental and neurocognitive research (Dodge and Lakoff 2005; Gibbs 2005; Gibbs and Colston 2006; Mandler 1992). A key finding in this literature is that the use of image schemas in working memory involves the reactivation of some of the very same perceptual and motor systems involved in the acquisition of that image schema (Barsalou 2016:1129; Ignatow 2007:121); this process is sometimes referred to as the principle of neural reuse (Anderson 2016). For example, the phrase "[o]nce he gets rolling, you'll never get him to stop talking" (Gibbs and Colston 2006:262) activates the same MOMENTUM ${ }^{9}$ schema that would be activated if the body were actually experiencing momentum. In this way, basic image schemas serve as source domains for analogical meaning-making. This grounding of abstract domains in experientially basic domains is part of the recent inter-disciplinary convergence on the fundamental "embodiment" of cognition (Barsalou 2008; Cerulo 2015; Glenberg 2010; Ignatow 2007; Lizardo 2009; Pitts-Taylor 2015; Wilson 2002).

Although image schemas are simple and acquired through early recursive exposure to and navigation/manipulation of the world, they are important for sociological analysis because they structure the meanings of more experience-distant aspects of life, such as complex social processes and abstract concepts (Hertz 2013; Kövecses 2005b, 2010, 2015; Lakoff and Johnson 2008 [1980]; Schwartz 1981; Turner 1996). ${ }^{10}$ For example, Schwartz (1981) finds that many

\footnotetext{
${ }^{9}$ Following the convention of cognitive semantics, we use small capital letters to refer to the names of image schemas.

${ }^{10}$ Lakoff and Johnson's theory of enculturation and cognition is consistent with other sociological approaches, including Durkheim's oft misunderstood “argument for the social origins of the categories of the understanding" (Rawls 1996:430), which locates "the origin of the fundamental categories of thought in the concrete empirical details of enacted practices" (Rawls 1996:430; cf. Martin 2011:112-131). Similarly, Barry Schwartz (1981; see also Schwartz, Tesser, and Powell 1982), in his study of "vertical
} 
cultures understand the abstract concepts of morality and power in terms of verticality, associating UP with moral goodness and power and DOWN with immorality and weakness. Hence, gods, heavens, and heavenly powers are typically located above, while demons, hell, and evil forces are found below (Schwartz 1981:71; Lizardo 2009:615). Similarly, good people are often talked about as being upright (though they can fall into a low place after an immoral act [Kövecses 2005a:152]), and the U.S. Supreme Court is the high authority that overrules the lower courts (Winter 1989:1145).

When image-schematic mappings are conventionalized, actors may use them strategically to evoke certain meanings. In the case of verticality, for example, something as subtle as whether the name of a group appears on the top or bottom of a computer screen can influence how people evaluate the powerfulness of the group (Schubert 2005). Historically, political actors have used verticality to signal their relative social position, for example, by placing palaces atop hills (Abrutyn 2014:105). Additionally, revolutionaries may exploit conventionalized verticality mappings by arguing that the high need to be taken down because of their base acts, and replaced with someone more suitable to that high office (Schwartz 1981:136-141). Stated more generally, the mapping from embodied experience to abstract domains undergirds much of the meaning-making of interest to sociologists (Winchester 2016).

Despite the interdisciplinary relevance of image schemas and the range of potentially productive applications within sociology, very few sociologists have used them analytically_although notable exceptions include Ignatow (2004, 2007), Frye (2012:1597), Lizardo (2012, 2013), and Feagin (2013:40). Instead, sociologists using the term "schema" tend

classification," arrives at the concept of "experiential prototypes" which is remarkably similar to Lakoff and Johnson's image schema concept. 
to describe more complex arrangements without considering the possibility that they comprise experiential primitives (Mandler 1992). Many typologies of schemas exist based on the degree of complexity, carrying a range of labels such as scripts, plans, stories, and indeed, even frames (e.g., Ghosh and Gilboa 2014; Mandler 2014; Schank and Abelson 2013). Alongside these, and following the anthropologist Bradd Shore (1998), we find the concept of foundational schema particularly useful for sociologists to understand and compare the organization of cultural knowledge across times, peoples, and places.

\section{Foundational Schemas}

Like image schemas, foundational schemas are transposable but may be more complex than image schemas. Shore (1998) argues that these are "foundational" not because they are the most basic, but because they are central to the organization of many distinct domains for specific times, places, and subgroups of people. For example, Shore argues (1998:54) that the "center-periphery" schema is foundational in Samoa, and the "modularity" schema is foundational for the contemporary United States.

In the case of Samoa, Shore finds that the center-periphery schema structures a wide range of social behaviors, with "the central malae (village green) and the outskirts of the village" serving as the key "references points in village orientation" (1998:270). The central malae is the locus of formal gatherings of chiefs, serious conversations, and sacred events, and the area is protected at night by chiefly edict. Outside the malae, by contrast, is the place for casual conversation and mundane activities, and in the peripheral areas of the village, certain behaviors 
which are severely punished if they occur on the malae are tacitly accepted or understood to “have their 'proper' expressions" (1998:271-272).

Shore argues that the "modularity schema" is foundational in the United States, as evident in the American tendency to approach design tasks by "[breaking] complex wholes into elementary units that are understood to be recombinable in a variety of different patterns" (1998:118). Shore finds the modularity schema at work in a variety of American institutions, including shopping malls ("interchangeable spaces on huge reconfigurable floor plans"), hamburgers ("variable configuration[s] of... mass-produced beef building blocks"), and television channels ("virtual worlds with no bridges between them," divided into "segments" and “time slots"), among others (see 1998:121-125). Drawing on the historical-comparative work of John Blair (1988), Shore argues that modularity gained prominence in the United States as the result of Americans' recursive exposure to machine-mediated environments, and is foundational precisely because it can be found as an underlying organizational principle in so many settings.

\section{FRAMES}

\section{What are Frames?}

The first use of the "frame" concept can be traced back to the literary theorist Kenneth Burke's (1984 [1937]) Attitudes Toward History, in which he argues that all "poetic forms" in history can be reduced to two "frames of reference" (acceptance and rejection). Although he offers little elaboration, Burke considers frames to be "major psychological devices whereby the mind equips itself to name and confront its situation" (1984:99). Later, the anthropologist 
Gregory Bateson used the concept to explain the behavior of the monkeys he observed at the Fleishhacker Zoo in 1952. Similar to Burke, Bateson argued that monkeys have "psychological frames" for a "real fight" and a "play fight," and they also were capable of "exchanging signals" indicating which is operative (Bateson 1955). In linguistics, Charles Fillmore, attempting to challenge so-called "checklist" approaches to word meaning (1975), argued the meaning of individual words could only be specified in relation to a semantic "frame," but used this term interchangeably with “schema” (1976:25). Later, the cognitive psychologist Barsalou (1992) selected "frame" to refer to particularly well-formed memory structures (but considers it equivalent to schema). In his well-known treatise, Sensemaking in Organizations, the organizational theorist Karl Weick (1995)—building on Starbuck and Milliken (1988)—argued that "frames" are essential to the process of "sensemaking," but does not provide any clear definition.

It is well known that the concept entered sociology via Goffman, who borrowed it directly from Bateson, and used 'the term 'frame' in roughly the sense in which he [Bateson] meant it" (Goffman 1981:64). Since Goffman's Frame Analysis, sociologists have used the concept of a frame to empirically analyze a wide range of phenomena, including social movements (Snow et al. 1986), poverty (Young 2010), education (Davies 2002), historical networks (McLean 1998), business discourse (Ghaziani and Ventresca 2005), small-group conversations (Kretsedemas 2000), racism (Taylor and Rambo 2013), and sociocultural evolution (Abrutyn, Van Ness, and Taylor 2016).

Building on Goffman's work, some scholars have held close to the initial formation, using the concept as roughly equivalent to schemas (e.g. Oliver and Johnston 2000). Many 
seminal works in frame analysis have defined frames as explicitly cognitive objects that individual actors possess; they are "“schemata of interpretation' that enable individuals 'to locate, perceive, identify, and label' occurrences within their life space" (Snow et al. 1986:464, with quotes from Goffman 1974:21), and "persistent patterns of cognition, interpretation, and presentation ... by which symbol-handlers routinely organize discourse" (Gitlin 1980:7).

Many others, however, have departed from this tradition by conceptualizing frames as public objects - i.e., as a form of public culture rather than something personal. Following these formulations, a frame is a shared definition of a situation that emerges in concrete social interaction (Tannen and Wallat 1987:206-7), consisting of arranged elements that make up an "interpretive package" (Gamson and Modigliani 1989), and which crystallizes as "the outcome of negotiating" (Benford and Snow 2000:614; Gamson 1992:111). As more contemporary observers note, a frame (in the latter usage) is a "general meaning context within which social actors interpret action" (Brekhus 2015:11).

As a public object-an external "setting" or distributable "thing"-a frame is said to "[provide] an interpretive 'footing' that aligns schemas that participants to the interaction bring with them" (Benford and Snow 2000:614). Thus, we see in this latter approach a possible criterion to distinguish between frames and schemas, where frames are taken as public aligners and schemas are either ignored or are taken as the personal things being aligned. Outside of sociology, some have maintained this analytical distinction while continuing to use the term "frame" to refer to both forms. For example, Kinder and Sanders (1990:74) note that "frames lead a double life: they are internal structures of the mind that help individuals to order and give meaning ... [and] they are also devices embedded in political discourse . . . intended to make 
favorable interpretations prevail." Adding some clarity, Chong and Druckman (2007:106; 2001:227-228) refer to these two different forms of the frame concept as frames in thought and frames in communication (see also Bizer, Larsen, and Petty 2011; Borrelli and Lockerbie 2008; Kahneman and Tversky 1979; Kelly 2012; Tversky and Kahneman 1981).

We consider frames as a form of public culture distinct from schemas, but depart from previous definitions insofar as we see frames as distinctly material and situational. In our formulation, frames are situational assemblages of material objects (i.e. public culture), which activate networks of schemas (i.e. personal culture) in receivers (for an equivalent distinction see DiMaggio 1997:274). Following cultural sociologists studying materiality (e.g., Griswold et al. 2013; McDonnell 2010), under the label "objects" we include everything from books, billboards, boulders, and buildings, to human and non-human bodies, from vibrations, sounds, and conversations, to sunlight, dirt, and the stench wafting from a dumpster-indeed, anything tangible.

As assemblages of the material objects in a given situation, frames reside between the standpoints of a sender(s) and a receiver(s), ${ }^{11}$ and may consist of any perceptible medium, such as arrangements of words on a page or people on a stage, the interior design of a classroom, color schemes used in billboards, musical compositions of national anthems, or arrangements of lighting and smells in a restaurant. Given that we conceptualize frames as material assemblages, our definition excludes "internalized" forms of culture such as beliefs-i.e., embodied

${ }^{11}$ Goffman (1959) often interchangeably defined the receiver position in a situation as either the audience or observer and the sender as a performer, actor, or team. Any number of relational terms that imply the directional diffusion of a framing process could work here depending on the substantive and empirical context, such producer-consumer in the sociology of consumption or ego-alter in social network theory. 
expectations and anticipations (Strand and Lizardo 2015) - and meanings -i.e., "the interpretation[s] evoked in a person by an object or event" (Strauss and Quinn 1997:6 see also Spiro 1987).

However, as previously outlined, objects of cultural analysis often have both internalized and externalized dimensions (e.g., Lizardo 2016:200). Actors continually offload evidence of beliefs and meanings into the material environment so as to "ease cognition" (Martin 2010:237) and communicate. As such, frames carry affinities to the schemas that were used in constructing the frame, as well as the schemas which are activated by exposure to the frame. Relatedly, declarative representations of beliefs are often front-and-center in the "instructions" for composing a frame - a topic to which we now turn.

\section{Models of Frames and Frame Composition}

Apart from composing a frame, actors may develop a model of a frame (see Table 2). A model of a frame is a simplified set of declarative instructions or nondeclarative abilities used to recreate a frame, and may be said to be "cultural" to the extent that they are learned and shared. While a model of a frame is based on schemas, as knowledge or skill, these models are more content-rich. In its declarative form, models of frames can be articulated and made public by, for example, being drawn out, expressed in spoken form, or written down as a set of instructions.

\section{[Table 2. About Here]}

A model of a frame is not the frame itself, but the knowledge or ability to compose and/or describe the frame. Models of frames may vary in specificity, and may be created either deliberately or automatically as a result of repeated exposure to a frame (e.g. knowing what to do 
habitually). Models of frames constructed in an deliberative fashion may be the result of group negotiation. For example, when protest organizers explicitly discuss how they should present themselves and their message to the public (e.g. Benford 1993), they are deliberately constructing a model of a frame. This model may then be used when the movement organizers assemble the publicly available frame during the actual protest. This is to say, in the proposed framework, the subject of Benford's (1993) empirical research would be frame modeling rather than framing, because his data capture the deliberative process through which actors construct a model of a frame in anticipation of a future framing situation. In approximate terms, frame modeling may be understood as developing a plan or developing a skill, while framing may be understood as the executing of a plan or skill. This distinction is most apparent when there is a temporal gap between planning and executing, but these processes often overlap empirically. ${ }^{12}$ Alternatively, models of frames may develop automatically through repeated experience assembling frames. For example, much of the work of fashion model bookers involves putting together just the right assortment of models for a particular job. Skilled bookers position themselves as the "precarious tastemaker[s]" who can instinctively "recognize the look" when they see it (Mears 2011:171), despite having a hard time articulating what constitutes "the look"-i.e., the particular constellation of archetypical features sought after among models.

Models of frames can exist in both declarative and nondeclarative forms. However, it is possible for models of frames to exist mainly as declarative instructions (with no corresponding nondeclarative know how), or as purely nondeclarative skill without a corresponding declarative form. As an example of the latter situation, a skilled orator, drawing on a nondeclarative model

\footnotetext{
${ }^{12}$ The overlap between modeling and framing is especially likely with nondeclarative modeling, where frame modeling consists of developing nondeclarative embodied skill through the actual doing of the act (i.e., engaging in framing), as exemplified by the phrase "learning by doing."
} 
of speech giving, may assemble a frame which evokes strong emotions, but she may do so without knowing precisely "what" makes her speech effective. Thus, actors may assemble frames (what we refer to as framing) using either automatic or deliberative processing, depending on whether the relied upon model is declarative or nondeclarative.

[Table 3. About Here]

\section{THE EVOCATION MODEL: HOW DO FRAMES WORK?}

In the work of sociologists who treat frames as a form of public culture, it is not clear exactly what frames do and how they accomplish these tasks. In some formulations, frames are carefully crafted sets of beliefs and meanings facilitating collective action by bringing together individuals and organizations who share congruent or complementary beliefs and meanings. In this case, the frame is a passive object attracting similarly-minded individuals. The frame is raised up like a banner, and the job of movement organizers is to make sure that the right people see the frame, or to adjust the frame so that more people are attracted to it (Snow et al. 1986).

In other accounts, the frame is considered a public interpretative tool. When individual followers "adopt" such a frame, they come to interpret the world in the same way as other group members. For example, reflecting on his research on the Nichiren Shoshu Buddhist movement, Snow writes, the "testimonies of member after member provide examples of their reinterpretation — that is, realignment—of aspects of their biographies... in ways that were in accord with the movement's informing point of view..." (Snow et al. 2014:25).

In both articulations frames may be said to "align" actors, but the meaning of "align" differs between "bringing together people who think the same way" and "providing a model so 
as to interpret the situation in the same way." One might contend that the same frame could both attract adherents and alter their perceptions of the world; but, one is left puzzling how exactly this works, and in turn, wondering when the analyst is witnessing one process or the other.

If we step back and reflect on these approaches, we see that we are a far cry from the simple understanding that frames influence thought. In fact, these approaches leave little room for frames to do such work. In the first formulation frames merely attract similarly-minded individuals, and in the second formulation, frames are passive modes of interpretation as they may or may not be adopted. One benefit of our analytical distinction between schemas and frames is it allows us to propose a more parsimonious and precise conceptualization of what frames do and how they work.

Thus, we suggest the following: Frames are situational assemblages of material objects (including bodies and settings) that evoke certain responses from individuals, in part by activating particular sets of schemas. Framing refers to the process of assembling a frame in situ, which typically entails the deployment of a declarative or nondeclarative model of a frame.

The evocation model is built upon three central analytic distinctions. First, we distinguish between frames and schemas and the work that they do. This distinction breaks with approaches that give frames the double role of being publicly negotiated interpretations and internalized models for interpretation. Second, our approach distinguishes between frames and models of frames. This carries two implications: first, as situational assemblages of material objects, frames cannot be internalized; nevertheless, a model of a frame (as declarative or nondeclarative knowledge or skill used in composing a frame) can be. One can memorize explicit instructions or actions for constructing situations in ways which can evoke desired responses in audiences. For 
example, a stagehand can memorize the instructions for assembling a venue for a small concert in ways to evoke the desired outcomes in audiences. These models may be used to reproduce a frame in different situations. In addition, our approach distinguishes between framing, defined as the assembling of a frame in situ, from frame modeling, defined as the development of a model of a frame, either deliberately or habitually.

Our evocation model of framing is not a radical departure from previous formulations, but rather makes explicit what was implicit or unclear in previous formulations and addresses their inconsistencies. First, our approach assumes that frames cause something in everyone who encounters them, regardless of the actors' social positions or experiences. Though we recognize that individuals may vary (perhaps widely) in their response to a given frame, it is assumed that frames will always evoke a response. Second, our framework relies on the processes of activation and evocation to describe the work that frames do, rather than internalization, transmission, or imposition. Frames activate sets of interrelated schemas-ranging from transposable image schemas and foundational schemas, to more complex and domain-specific schemas - which, once active, evoke a response. Third, our framework explicitly extends the sensory possibilities of frame far beyond most past usage (e.g., from text and speech to a multimodal approach which can capture all senses).

Our evocation model suggests that, when actors actively engage in framing, it is less about getting other people to "adopt" a frame and more about composing a frame. When intentionally composing a frame, the actor or team hopes an encounter with the particular material arrangement will evoke a desired response in an audience (Stoltz and Taylor 2017). For example, the generic political "march" involves people walking as a group toward a place of 
some symbolic significance. The marching may activate schemas for forward MOMENTUM, MERGING, and SOURCE + PATH+GOAL, which, in turn, may evoke a sense of progress and solidarity among the marchers.

Our evocation model also leaves room for confrontational framing and counter-framing. Opposing actors may try to rearrange the same objects in contrasting ways (e.g., pugilists bobbing, weaving, and swinging their bodies for judges or spectators) or use different assemblages entirely (e.g., lawyers offering distinctly assembled presentations of evidence and arguments in front of a jury). We argue that in such cases, oppositional actors are not applying different interpretive packages to what is essentially the same situation, but rather creating entirely new situations.

The evocation model also presents a straightforward way of understanding the contingencies of framing. A careful actor using a particular model of a frame may painstakingly arrange objects into a particular frame in order to evoke a desired audience response, but any number of things may occur which frustrate this goal. For example, one of the authors recalls an amusement park ride which created a frame designed to evoke for the rider the sensation of flying above a California landscape. The frame was assembled with several interacting elements: riders sat in one of three stacked rows of chairs that left their feet dangling. When the ride began, the rows were elevated and moved forward to be almost surrounded by an enormous concave screen. During the ride, the chairs subtly moved and tilted with the projected video, and a hidden device emitted fragrances that matched the landscape below (e.g., orange scent over an orange grove and pine scent over a forest). The first time the author went on the ride, he was sitting on the top row. The next time, he was sitting in one of the lower rows, and the effect was less 
impressive. For riders in the lower rows, the frame included the dangling and kicking feet of the riders above, which hindered the ability to be completely "taken in" by the simulation. In other words, the ride produced two different frames (one with dangling feet and one without), despite perhaps intending to compose only one frame for all riders. In this way, flaws or oversights in a model of a frame may result in unexpected frames when enacted during the framing process. Additionally, because frames are composed through material objects, frames may change in unintended ways when a situation's materials change or fail (McDonnell 2016). As most amusement-park-goers can attest, rides commonly break down. ${ }^{13}$

\section{SUGGESTIONS FOR FUTURE RESEARCH}

\section{[Table 4 About Here]}

To close, we briefly discuss productive avenues for empirical research that correspond to the four aspects of frame analysis as defined in our evocation model: frames, models of frames, framing, and frame modeling (see Table 4). This is not an exhaustive list, but a portrait of the potential stemming from our set of analytic distinctions and the evocation model.

Analysts studying framing might first focus on the motivation for framing. What do actors intend to achieve through assembling the material of a situation? Then, analysts might compare framing motivations with how actors actually assemble frames. We note that this process is not necessarily limited to social dynamics through interaction. Much of the work of

\footnotetext{
${ }^{13}$ Besides contingency in framing, one may also ask about the contingency of frame effects. Certain factors, such as a situation's emotional climate (Van Ness and Summers-Effler 2016) and the distribution of attention (Goffman 1963; Collins 2004; Stoltz and Taylor 2017), might create variation in the schemas a frame evokes, but these questions lie beyond the scope of this paper.
} 
assembling the frame may be done by non-human material objects, as in the case of automated theme-park rides that more or less reliably produce the same assemblage of objects hour after hour, day after day. Finally, analysts might study the contingency of framing, including discrepancies between carefully constructed models of frames and actually assembled frames in situ.

Researchers studying frame modeling might investigate how actors (including analysts) create models of frames. This area of research might benefit from analyzing variation in the cognitive pathways used in learning or thinking (e.g., following the dual-process framework [Lizardo et al. 2016]) and the social organization that supports these processes (e.g., Van Ness and Summers-Effler 2016). Additionally, one could investigate the factors which affect the process of frame modeling, such as actors' future projections about anticipated framing situations. Finally, researchers might investigate why actors rely on conventional models to compose frames in some scenarios, while creating entirely new models in others.

As it relates to models of frames, a researcher might identify the lay models of frames that actors use when assembling particular frames. For example, one could ask, what models of frames do real estate agents use when staging a house (Vercel n.d.)? On what elements do they focus? Alternatively, a researcher might construct a formal model of an actual frame itself. That is, recognizing that a particular frame evoked a particular response, the researcher might ask, what was it about this frame that caused this outcome? Which elements or relations of elements were significant?

Finally, regarding frame, a researcher might study contingency in frame effects—why it is that different people sometimes respond differently to a given frame. One likely possibility is 
that in some cases, a frame evokes a particular response because it violates a particular cultural model, such that the frame evokes a response only in those that share a similar model. For example, a cinematographer may prolong a shot far longer than is typical, which would disorient someone who has a "sense" for how long a shot should last but maybe not someone who is new to cinema.

We conclude by emphasizing the cognitive foundations of theory construction itself (Swedberg 2014). In particular, we wish to emphasize that because words are not concepts but rather refer to concepts (Martin 2011), we are not ideologically tied to the textual labels we choose to denote our underlying concepts. We do, however, stress that if one wishes to use "frame" as a situational material configuration (and therefore public), the analyst cannot do without some consideration of the organization of (personal) culture which actors bring with them to the situation (e.g., schemas), as well as the interactional processes - in terms of framing and frame modeling - involved in both production and reception of the frame.

\section{REFERENCES}

Abrutyn, Seth. 2014. Revisiting Institutionalism in Sociology: Putting the "Institution" Back in Institutional Analysis. New York: Routledge.

Abrutyn, Seth, Justin Van Ness, and Marshall A. Taylor. 2016. "Collective Action and Cultural Change: Revisiting Eisenstadt's Evolutionary Theory.” Journal of Classical Sociology 16(4):369-95.

Anderson, Michael L. 2016. "Précis of After Phrenology: Neural Reuse and the Interactive Brain." The Behavioral and Brain Sciences 39:1-45.

d'Andrade, Roy G. 1995. The Development of Cognitive Anthropology. New York: Cambridge University Press.

Axelrod, Robert. 1973. "Schema Theory: An Information Processing Model of Perception and 
Cognition.” The American Political Science Review 67(04):1248-66.

Barsalou, Lawrence W. 2008. "Grounded Cognition.” Annual Review of Psychology 59(1):617-45.

Barsalou, Lawrence W. 1992. "Frames, Concepts, and Conceptual Fields." Pp. 21-74 in Frames, Fields, and Contrasts: New Essays in Semantic and Lexical Organization. Edited by A. Lehrer and E. F. Kittay. Hillsdale, NJ: Lawrence Erlbaum Associates.

Barsalou, Lawrence W. 2016. "On Staying Grounded and Avoiding Quixotic Dead Ends." Psychonomic Bulletin \& Review 23(4):1122-42.

Bartlett, Frederic Charles. 1932. Remembering: A Study in Experimental and Social Psychology. New York: Cambridge University Press.

Bateson, Gregory. 1955. "A Theory of Play and Fantasy.” Psychiatric Research Reports 2(3):39-51.

Benford, Robert D. 1993. "Frame Disputes within the Nuclear Disarmament Movement." Social Forces 71(3):677-701.

Benford, Robert D. and David A. Snow. 2000. "Framing Processes and Social Movements: An Overview and Assessment." Annual Review of Sociology 26(1):611-39.

Bizer, George Y., Jeff T. Larsen, and Richard E. Petty. 2011. "Exploring the Valence-Framing Effect: Negative Framing Enhances Attitude Strength.” Political Psychology 32(1):59-80.

Blair, John G. 1988. Modular America: Cross-Cultural Perspectives on the Emergence of an American Way. Santa Barbara, CA: Praeger.

Bloch, Maurice. 2015. In and Out of Each Other's Bodies: Theory of Mind, Evolution, Truth, and the Nature of the Social. New York: Routledge.

Borrelli, Stephen A. and Brad Lockerbie. 2008. "Framing Effects on Public Opinion during Prewar and Major Combat Phases of the US Wars with Iraq." Social Science Quarterly 89(2):502-22.

Boutyline, Andrei. 2016. "Improving the Measurement of Shared Cultural Schemas with Correlational Class Analysis: Theory and Method.” Sociological Science 4:353-93.

Brekhus, Wayne H. 2015. Culture and Cognition: Patterns in the Social Construction of Reality. Malden, MA: Polity Press.

Burke, Kenneth. 1984. Attitudes Toward History. Berkeley, CA: University of California Press.

Cerulo, Karen A. 2010. "Mining the Intersections of Cognitive Sociology and Neuroscience." 


\section{Poetics 38(2):115-32.}

Cerulo, Karen A. 2014. "Continuing the Story: Maximizing the Intersections of Cognitive Science and Sociology.” Sociological Forum 29(4):1012-19.

Cerulo, Karen A. 2015. "The Embodied Mind: Building on Wacquant's Carnal Sociology." Qualitative Sociology 38(1):33-38.

Chong, Dennis and James N. Druckman. 2007. "Framing Theory." Annual Review of Political Science 10(1):103-26.

Cicourel, Aaron V. 1981. "The Role of Cognitive-Linguistic Concepts in Understanding Everyday Social Interactions.” Annual Review of Sociology 7(1):87-106.

Davies, Scott. 2002. “The Paradox of Progressive Education: A Frame Analysis.” Sociology of Education 75(4):269-86.

DiMaggio, Paul. 1997. “Culture and Cognition.” Annual Review of Sociology 23(1):263-87.

Dodge, Ellen and George Lakoff. 2005. "Image Schemas: From Linguistic Analysis to Neural Grounding." Pp. 57-91 in From Perception to Meaning: Image Schemas in Cognitive Linguistics. Edited by B. Hampe. Berlin: Mouton de Gruyer.

Dominguez-Rubio, Fernando. 2014. "Preserving the Unpreservable: Docile and Unruly Objects at MoMA." Theory and Society 43(6):617-45.

Druckman, James N. 2001. "The Implications of Framing Effects for Citizen Competence." Political Behavior 23(3):225-56.

Feagin, Joe R. 2013. The White Racial Frame: Centuries of Racial Framing and Counter-Framing. New York: Routledge.

Fillmore, Charles J. 1975. “An Alternative to Checklist Theories of Meaning.” Pp. 121-31 in Proceedings of the First Annual Meeting of the Berkeley Linguistics Society. Berkeley, CA.

Fillmore, Charles J. 1976. "Frame Semantics and the Nature of Language." Annals of the New York Academy of Sciences 280(1):20-32.

Frye, Margaret. 2012. "Bright Futures in Malawi's New Dawn: Educational Aspirations as Assertions of Identity.” American Journal of Sociology 117(6):1565-1624.

Gamson, William A. 1992. Talking Politics. New York: Cambridge University Press.

Gamson, William A. and Andre Modigliani. 1989. "Media Discourse and Public Opinion on Nuclear Power: A Constructionist Approach.” American Journal of Sociology 95(1):1-37.

Ghaziani, A., \& Ventresca, M. J. 2005. "Keywords and cultural change: Frame analysis of 
business model public talk, 1975-2000." Sociological Forum 20(4):523-559.

Ghosh, Vanessa E. and Asaf Gilboa. 2014. "What Is a Memory Schema? A Historical Perspective on Current Neuroscience Literature." Neuropsychologia 53:104-14.

Gibbs, Raymond W. 2005. "The Psychological Status of Image Schemas.” Pp. 113-36 in From Perception to Meaning: Image Schemas in Cognitive Linguistics. Edited by B. Hampe. Berlin: Mouton de Gruyer.

Gibbs, Raymond W. and Herbert L. Colston. 2006. "Image Schema: The Cognitive and Psychological Reality of Image Schemas and their Transformations." Pp. 239-68 in Cognitive Linguistics: Basic Readings. Edited by D. Geeraerts. Berlin: Mouton de Gruyter.

Giddens, Anthony. 1979. Central Problems in Social Theory: Action, Structure, and Contradiction in Social Analysis. Berkeley, CA: University of California Press.

Glenberg, Arthur M. 2010. "Embodiment as a Unifying Perspective for Psychology." WIREs Cognitive Science 1(4):586-96.

Goffman, Erving. 1974. Frame Analysis: An Essay on the Organization of Experience. Harvard Cambridge, MA: University Press.

Goffman, Erving. 1981. “A Reply to Denzin and Keller.” Contemporary Sociology 10(1):60-68.

Goldberg, Amir. 2011. "Mapping Shared Understandings Using Relational Class Analysis: The Case of the Cultural Omnivore Reexamined." American Journal of Sociology 116(5):1397-1436.

Griswold, Wendy, Gemma Mangione, and Terence E. McDonnell. 2013. "Objects, Words, and Bodies in Space: Bringing Materiality into Cultural Analysis." Qualitative Sociology 36(4):343-64.

Hertz, Robert. 2013. Death and the Right Hand. New York: Routledge.

Hutto, Daniel D. and Erik Myin. 2012. Radicalizing Enactivism: Basic Minds without Content. Cambridge, MA: The MIT Press.

Hutto, Daniel D. and Erik Myin. 2017. Evolving Enactivism: Basic Minds Meet Content. Cambridge, MA: The MIT Press.

Iacoboni, Marco. 2009. "Imitation, Empathy, and Mirror Neurons." Annual Review of Psychology 60(1):653-70.

Ignatow, Gabriel. 2004. "Speaking Together, Thinking Together? Exploring Metaphor and Cognition in a Shipyard Union Dispute." Sociological Forum 19(3):405-33.

Ignatow, Gabriel. 2007. “Theories of Embodied Knowledge: New Directions for Cultural and 
Cognitive Sociology?" Journal for the Theory of Social Behaviour 37(2):115-35.

Johnson, Mark. 2013. The Body in the Mind: The Bodily Basis of Meaning, Imagination, and Reason. Chicago, IL: University of Chicago Press.

Kahneman, Daniel and Amos Tversky. 1979. "Prospect Theory: An Analysis of Decision under Risk." Econometrica: Journal of the Econometric Society 47(2):263-91.

Kant, Immanuel. 1998 [1781]. Critique of Pure Reason. Translated by P. Guyer and A. W. Wood. New York: Cambridge University Press.

Kelly, Jamie Terence. 2012. Framing Democracy: A Behavioral Approach to Democratic Theory. Princeton, NJ: Princeton University Press.

Kinder, Donald R. and Lynn M. Sanders. 1990. "Mimicking Political Debate with Survey Questions: The Case of White Opinion on Affirmative Action for Blacks." Social Cognition $8(1): 73-103$.

Klett, Joseph. 2014. "Sound on Sound: Situating Interaction in Sonic Object Settings." Sociological Theory 32(2):147-161.

Kövecses, Zoltán. 2005a. "A Broad View of Cognitive Linguistics." Acta Linguistica Hungarica 52(2-3):135-72.

Kövecses, Zoltán. 2005b. Metaphor in Culture: Universality and Variation. New York: Cambridge University Press.

Kövecses, Zoltán. 2010. Metaphor: A Practical Introduction. New York: Oxford University Press.

Kövecses, Zoltán. 2015. Where Metaphors Come From: Reconsidering Context in Metaphor. New York: Oxford University Press.

Kretsedemas, Philip. 2000. "Examining Frame Formation in Peer Group Conversations." The Sociological Quarterly 41(4):639-56.

Lakoff, George. 2008. Women, Fire, and Dangerous Things. Chicago, IL: University of Chicago Press.

Lakoff, George and Mark Johnson. 1980. "The Metaphorical Structure of the Human Conceptual System.” Cognitive Science 4(2):195-208.

Lakoff, George and Mark Johnson. 2008. Metaphors We Live by. Chicago, IL: University of Chicago Press.

Lizardo, Omar. 2004. "The Cognitive Origins of Bourdieu's Habitus." Journal for the Theory of 
Social Behaviour 34(4):375-401.

Lizardo, Omar. 2009. “The Devil as Cognitive Mapping.” Rethinking Marxism 21(4):605-18.

Lizardo, Omar. 2009. "Is a 'Special Psychology' of Practice Possible?: From Values and Attitudes to Embodied Dispositions.” Theory \& Psychology 19(6):713-27.

Lizardo, Omar. 2012. "The Conceptual Bases of Metaphors of Dirt and Cleanliness in Moral and Non-Moral Reasoning." Cognitive Linguistics 23(2):367-93.

Lizardo, Omar. 2013. "Re-Conceptualizing Abstract Conceptualization in Social Theory: The Case of the 'Structure' Concept." Journal for the Theory of Social Behaviour 43(2):155-80.

Lizardo, Omar. 2014. "Beyond the Comtean Schema: The Sociology of Culture and Cognition Versus Cognitive Social Science.” Sociological Forum 29(4):983-89.

Lizardo, Omar. 2016. “Cultural Symbols and Cultural Power.” Qualitative Sociology 39(2):199-204.

Lizardo, Omar. 2017. "Improving Cultural Analysis: Considering Personal Culture in Its Declarative and Nondeclarative Modes." American Sociological Review 82(1):88-115.

Lizardo, Omar, Robert Mowry, Brandon Sepulvado, Dustin S. Stoltz, Marshall A. Taylor, Justin Van Ness, and Michael Wood. 2016. "What Are Dual Process Models? Implications for Cultural Analysis in Sociology." Sociological Theory 34(4):287-310.

Mandler, Jean M. 1978. "A Code in the Node: The Use of a Story Schema in Retrieval." Discourse Processes 1(1):14-35.

Mandler, Jean M. 1992. "How to Build a Baby: II. Conceptual Primitives." Psychological Review 99(4):587-604.

Mandler, Jean M. 2014. Stories, Scripts, and Scenes: Aspects of Schema Theory. New York: Psychology Press.

Mandler, Jean M. and Cristóbal Pagán Cánovas. 2014. “On Defining Image Schemas.” Language and Cognition 6(4):510-32.

Martin, John Levi. 2010. "Life's a Beach but You're an Ant, and Other Unwelcome News for the Sociology of Culture." Poetics 38(2):229-44.

Martin, John Levi. 2011. The Explanation of Social Action. New York: Oxford University Press.

McDonnell, Terence E. 2010. "Cultural Objects as Objects: Materiality, Urban Space, and the Interpretation of AIDS Campaigns in Accra, Ghana." American Journal of Sociology 115(6):1800-1852. 
McLean, Paul D. 1998. "A Frame Analysis of Favor Seeking in the Renaissance: Agency, Networks, and Political Culture.” American Journal of Sociology 104(1):51-91.

Mears, Ashley. 2011. Pricing Beauty: The Making of a Fashion Model. Berkeley, CA: University of California Press.

Minsky, Marvin. 1974. “A Framework for Representing Knowledge.” Artificial Intelligence, memo number 306. Cambridge, MA: Massachusetts Institute of Technology A.I. Laboratory.

Oliver, Pamela and Hank Johnston. 2000. "What a Good Idea! Ideologies and Frames in Social Movement Research.” Mobilization 5(1):37-54.

Parsons, Talcott. 1935. "The Place of Ultimate Values in Sociological Theory." International Journal of Ethics 45(3):282-316.

Patterson, Orlando. 2014. "Making Sense of Culture.” Annual Review of Sociology 40(1):1-30.

Piaget, Jean. 1952. The Origins of Intelligence in Children. Translated by M. Cook. New York: International Universities Press.

Pitts-Taylor, Victoria. 2015. "A Feminist Carnal Sociology?: Embodiment in Sociology, Feminism, and Naturalized Philosophy.” Qualitative Sociology 38(1):19-25.

Rawls, Anne Warfield. 1996. "Durkheim's Epistemology: The Neglected Argument.” American Journal of Sociology 102(2):430-82.

Rumelhart, David E. 1975. "Notes on a Schema for Stories." Pp. 211-36 in Representation and Understanding: Studies in Cognitive Science. Edited by D. G. Bobrow and A. Collins. New York: Academic Press.

Rumelhart, David E. 1980. "Schemata: The Building Blocks of Cognition.” Pp. 33-58 in Theoretical Issues in Reading Comprehension: Perspectives from Cognitive Psychology, Linguistics, Artificial Intelligence, and Education. Edited by R. J. Spiro, B. C. Bruce, and W. F. Brewer. Hillsdale, NJ: Lawrence Erlbaum Associates.

Rumelhart, David E. and Andrew Ortony. 1977. "The Representation of Knowledge in Memory." Pp. 99-135 in Schooling and the Acquisition of Knowledge. Edited by R. C. Anderson, R. J. Spiro, and W. E. Montague. Hillsdale, NJ: Lawrence Erlbaum Associates.

Schank, Roger C. and Robert P. Abelson. 2013. Scripts, Plans, Goals, and Understanding: An Inquiry Into Human Knowledge Structures. New York: Psychology Press.

Schmidt, Richard A. 1975. "A Schema Theory of Discrete Motor Skill Learning." Psychological Review 82(4):225.

Schubert, Thomas W. 2005. "Your Highness: Vertical Positions as Perceptual Symbols of 
Power." Attitudes and Social Cognition 89(1):1-21.

Schwartz, Barry. 1981. Vertical Classification: A Study in Structuralism and the Sociology of Knowledge. Chicago, IL: University of Chicago Press.

Schwartz, Barry, Abraham Tesser, and Evan Powell. 1982. "Dominance Cues in Nonverbal Behavior." Social Psychology Quarterly 45(2):114-20.

Sewell, William H. 1992. "A Theory of Structure: Duality, Agency, and Transformation.” American Journal of Sociology 98(1):1-29.

Shore, Bradd. 1991. "Twice-Born, Once Conceived: Meaning Construction and Cultural Cognition." American Anthropologist 93(1):9-27.

Shore, Bradd. 1998. Culture in Mind: Cognition, Culture, and the Problem of Meaning. New York: Oxford University Press.

Slater, Alan and Paul C. Quinn. 2001. "Face Recognition in the Newborn Infant." Infant and Child Development 10(1-2):21-24.

Snow, David A., Robert D. Benford, Holly McCammon, Lyndi Hewitt, and Scott Fitzgerald. 2014. "The Emergence, Development, and Future of the Framing Perspective: 25+ Years Since "Frame Alignment." Mobilization 19(1):23-46.

Snow, David A., E. Burke Rochford, Steven K. Worden, and Robert D. Benford. 1986. "Frame Alignment Processes, Micromobilization, and Movement Participation.” American Sociological Review 51(4):464-81.

Somers, Margaret R. 1999. "The Privatization of Citizenship: How to Unthink a Knowledge Culture." Pp. 121-61 in Beyond the Cultural Turn: New Directions in the Study of Society and Culture. Edited by V. E. Bonnell and L. Hunt. Berkeley, CA: University of California Press.

Sonnett, John. 2004. "Musical Boundaries: Intersections of Form and Content." Poetics $32(3-4): 247-64$.

Spillman, Lyn. 2016. "Culture's Coherence: How the Trees Compose the Woods." The American Sociologist 47(4):416-29.

Spiro, Melford E. 1987. Culture and Human Nature. Edited by B. Killborne and L. Langness. New Brunswick, NJ: Transaction Publishers.

Squire, Larry R. 2004. "Memory Systems of the Brain: A Brief History and Current Perspective." Neurobiology of Learning and Memory 82(3):171-77.

Squire, Larry R. 1992. "Declarative and Nondeclarative Memory: Multiple Brain Systems 
Supporting Learning and Memory." Journal of Cognitive Neuroscience 4(3):232-43.

Starbuck, William H. and Frances J. Milliken. 1988. “Executives' Perceptual Filters: What They Notice and How They Make Sense." Pp. 35-65 in The Executive Effect: Concepts and Methods for Studying Top Managers. Edited by D. Hambrick. Greenwich, CT: JAI Press.

Stoltz, Dustin S. and Marshall A. Taylor. 2017. "Paying with Change: The Purposeful Enunciation of Material Culture." Poetics 64:26-39.

Strand, Michael and Omar Lizardo. 2015. "Beyond World Images Belief as Embodied Action in the World." Sociological Theory 33(1):44-70.

Strauss, Claudia and Naomi Quinn. 1997. A Cognitive Theory of Cultural Meaning. New York: Cambridge University Press.

Swedberg, Richard. 2014. The Art of Social Theory. Princeton, NJ: Princeton University Press.

Swidler, Ann. 2001. "What Anchors Cultural Practices." Pp. 74-92 in The Practice Turn in Contemporary Theory. Edited by K. K. Cetina, T. R. Schatzki, and E. von Savigny. London: Routledge.

Swidler, Ann and Jorge Arditi. 1994. "The New Sociology of Knowledge." Annual Review of Sociology 20(1):305-29.

Taylor, Marshall A. and C. Rambo. 2013. "White Shame, White Pride: Emotional Cultures, Feeling Rules, and Emotion Exemplars in White Supremacist Movement Music." International Journal of Crime, Criminal Justice and Law 8(1-2):107-34.

Turner, Mark. 1996. The Literary Mind: The Origins of Thought and Language. New York: Oxford University Press.

Turner, Victor Witter. 1967. The Forest of Symbols: Aspects of Ndembu Ritual. Ithaca, NY: Cornell University Press.

Tversky, Amos and Daniel Kahneman. 1981. "The Framing of Decisions and the Psychology of Choice." Science 211(4481):453-58.

Vaisey, Stephen. 2009. "Motivation and Justification: A Dual-Process Model of Culture in Action 1." American Journal of Sociology 114(6):1675-1715.

Van Ness, Justin and Erika Summers-Effler. 2016. "Reimagining Collective Behavior." Pp. 527-46 in Handbook of Contemporary Sociological Theory, Handbooks of Sociology and Social Research. Edited by S. Abrutyn. Springer International Publishing.

Vercel, Kelcie L. N.d. "Feels Like a Home: How Home Stagers Attempt to Construct 'Livability' for Home Buyers." Unpublished manuscript. 
Weick, Karl E. 1995. Sensemaking in Organizations. Thousand Oaks, CA: Sage.

Wilson, Margaret. 2002. "Six Views of Embodied Cognition." Psychonomic Bulletin \& Review 9(4):625-36.

Winchester, Daniel. 2016. "A Hunger for God: Embodied Metaphor as Cultural Cognition in Action.” Social Forces 95(2):585-606.

Winter, Steven L. 1989. "Transcendental Nonsense, Metaphoric Reasoning, and the Cognitive Stakes for Law." University of Pennsylvania Law Review 137(4):1105-237.

Young, Alford A., Jr. 2010. "New Life for an Old Concept: Frame Analysis and the Reinvigoration of Studies in Culture and Poverty." The Annals of the American Academy of Political and Social Science 629(1):53-74. 


\section{TABLES}

Table 1. Definitions of Primary Concepts

\begin{tabular}{|c|c|}
\hline Schema & $\begin{array}{l}\text { A flexible memory structure, automatically acquired } \\
\text { and updated from patterned activity, composed of } \\
\text { multi-modal neural associations }\end{array}$ \\
\hline Image Schema & $\begin{array}{l}\text { A very basic schema stored in long-term memory } \\
\text { derived from repeated exposure to experiential } \\
\text { patterns. }\end{array}$ \\
\hline Foundational Schema & A culturally delimited, but highly transposable schema. \\
\hline Frame & $\begin{array}{l}\text { A situated assemblage of material objects capable of } \\
\text { activating schemas }\end{array}$ \\
\hline Framing & The assembling of a frame in a situation \\
\hline $\begin{array}{l}\text { Model of a } \\
\text { Frame }\end{array}$ & $\begin{array}{l}\text { The declarative instructions or nondeclarative skill } \\
\text { used to construct and/or describe a frame }\end{array}$ \\
\hline $\begin{array}{r}\text { Frame } \\
\text { Modeling }\end{array}$ & $\begin{array}{l}\text { The automatic or deliberative creation of a model of a } \\
\text { frame }\end{array}$ \\
\hline
\end{tabular}


Table 2. Distinctions between Framing and Frame Modeling

\begin{tabular}{clc}
\hline Process & Framing & Frame Modeling \\
\hline Product & Frame & Model of Frame \\
\hline
\end{tabular}


Table 3. Model of a Frame

\begin{tabular}{rll}
\hline Type of Model & Type of Frame Modeling & $\underline{\text { Examples }}$ \\
\hline Declarative Model & Deliberative/Conscious & $\begin{array}{l}\text { Instructions for organizing a } \\
\text { successful protest, or a plan } \\
\text { for how chorus members will } \\
\text { arrange their bodies on a } \\
\text { stage. }\end{array}$ \\
\hline Mondeclarative & Automatic/Unconscious & $\begin{array}{l}\text { Runway model bookers who } \\
\text { assemble line-ups using their } \\
\text { ability to spot "the look" } \\
\text { (Mears 2011), or book } \\
\text { publishers who who can spot } \\
\text { the next trend in popular } \\
\text { fiction }\end{array}$ \\
& & \\
& &
\end{tabular}


Table 4. Potential Research Questions

\begin{tabular}{lll}
\hline Process & Framing & Frame Modeling \\
& $\begin{array}{l}\text { What do actors hope to achieve } \\
\text { with their frame? }\end{array}$ & $\begin{array}{l}\text { How do actors create models of } \\
\text { frames? }\end{array}$ \\
$\begin{array}{l}\text { How do actors assemble } \\
\text { frames? }\end{array}$ & What factors influence this process? \\
$\begin{array}{ll}\text { What creates contingency in } \\
\text { this process? }\end{array}$ & $\begin{array}{l}\text { Under what conditions do actors use } \\
\text { conventional models/create new ones? }\end{array}$ \\
\hline Product & $\begin{array}{l}\text { Frame } \\
\text { Why do different people } \\
\text { respond differently to a given } \\
\text { frame? }\end{array}$ & $\begin{array}{l}\text { Model of Frame } \\
\text { observed frame effects? }\end{array}$ \\
& What models do actors use to produce a \\
\end{tabular}

